\author{
Abraham Siles* \\ Pontificia Universidad Católica del Perú \\ Lima, Perú \\ asiles@pucp.pe
}

\title{
Estudio de caso: breve evaluación preliminar sobre estado de emergencia en El Callao, a la luz del Derecho Constitucional peruano y el Derecho Internacional de los Derechos Humanos
}

\author{
Case study: short preliminary assessment of the current state \\ of emergency in El Callao, in the light of the Peruvian \\ Constitutional Law and International Law of Human Rights
}

*Profesor de Derecho Constitucional de la Pontificia Universidad Católica del Perú (PUCP), coordinador del Grupo de Investigación en Derecho Constitucional y Derechos Fundamentales (GIDCYDEF) de la PUCP, editor general de la revista Derecho PUCP. Correo electrónico: asiles@pucp.pe

\section{Resumen}

El artículo es un estudio de caso que evalúa el estado de emergencia recientemente instaurado y prorrogado de manera sucesiva en la Provincia Constitucional de El Callao (Perú), para enfrentar un problema de inseguridad ciudadana provocado por la delincuencia común y el crimen organizado. Revisa ciertos aspectos de la aplicación del instituto de excepción constitucional en la práctica, y en particular examina dos problemas centrales: de un lado, el de si la amenaza definida por el Ejecutivo supone una afectación a la vida de la nación y, de otro lado, el de si se respeta el principio de temporalidad; ambas, exigencias establecidas por la Constitución peruana y por el Derecho Internacional de los Derechos Humanos. El artículo concluye que no está justificado y es, más bien, ilegítimo el mantenimiento del estado de emergencia en El Callao, a la luz de la Constitución peruana y de los estándares del Derecho Internacional de los Derechos Humanos.

\section{Palabras clave}

Inseguridad ciudadana - estado de emergencia - régimen de excepción - afectación a la vida de la nación - principio de temporalidad.

** Texto basado en la ponencia presentada a las Primeras Jornadas Nacionales sobre Derechos Fundamentales (Lima, PUCP, 29 de septiembre de 2016). Artículo recibido el 26 de octubre de 2016 y aceptado para su publicación el 2 de diciembre de 2016.

N. de E: El estado de emergencia decretado en la Provincia Constitucional de El Callo a partir del 5 de diciembre de 2015 y prorrogado de forma sucesiva finalizó el 15 de octubre de 2016. 


\begin{abstract}
The article is a case study that assesses the state of emergency, recently introduced and extended successively in the Constitutional Province of Callao (Peru), to address a problem of public insecurity caused by common crime and organized crime. Revises certain aspects of the implementation of this institute of constitutional exception in practice, and in particular examines two central problems: on the one hand, whether the threat defined by the Executive supposes an affectation to the life of the nation and, on the other hand, that of whether the principle of temporality is respected; both requirements established by the Peruvian Constitution and the International Human Rights Law. The article concludes that it is not justified and rather illegitimate maintaining the state of emergency in El Callao, in the light of the Peruvian Constitution and standards of International Law of Human Rights.
\end{abstract}

\title{
Key words
}

Public security - state of emergency - regime of exception - affectation to the life of the nation - principle of temporality.

\section{Introducción}

Entre los deberes primordiales que la Constitución peruana asigna al Estado se hallan tanto el "garantizar la plena vigencia de los derechos humanos" como el "proteger a la población de las amenazas contra su seguridad" (artículo 44, Const.). La regulación conjunta de ambos deberes ${ }^{1}$ parece apuntar a la necesidad de entenderlos como complementarios, $\mathrm{y}$ no como opuestos. Es decir, la tutela de la efectividad de los derechos humanos o derechos fundamentales ${ }^{2}$ debe ir en consonancia con la protección que el Estado ha de proveer a las personas ante eventuales amenazas a su seguridad.

La Constitución, por lo demás, bajo el epígrafe de "Derechos fundamentales de la persona” (Capítulo I del Título I), igualmente regula de manera conjunta el derecho de todo ser humano "a la libertad y a la seguridad personales" (artículo, 2.24.f, Const.). Con ello parece recalcar, vigorosamente, la íntima vinculación entre estas dos dimensiones de los derechos esenciales de la persona. Dicho en otras palabras, la forma de la enunciación de estos derechos contribuye al significado de que libertad y seguridad, como derechos fundamentales, son elementos indisolublemente unidos e interdependientes.

Según el mismo artículo constitucional, otros cometidos esenciales a cargo del Estado son la defensa de la soberanía nacional y la promoción del bienestar general fundado en la justicia y en el desarrollo integral y equilibrado de la Nación.

2 Sobre la equiparación o tratamiento homogéneo de los dos conceptos por la Constitución peruana, véase CASTILLO (2005a), pp. 58-59; HAKANSSON (2009), pp. 418-420. 
Por cierto, esta regulación unitaria también se observa en los tratados internacionales de derechos humanos. Así, el artículo 7.1 de la Convención Americana sobre Derechos Humanos $(\mathrm{CADH})$ estipula que "toda persona tiene el derecho a la libertad y seguridad personales", mientras el artículo 9.1 del Pacto Internacional de Derechos Civiles y políticos (PIDCP) indica que "todo individuo tiene derecho a la libertad y seguridad personales".

Conviene tener en cuenta esta unidad e interdependencia entre seguridad y libertad de la persona y entre derechos humanos y seguridad de la población, apuntalada desde los propios enunciados constitucionales y los instrumentos del Derecho Internacional de los Derechos Humanos (DIDH), al procurar hacer una evaluación del estado de emergencia que fue declarado la Provincia Constitucional de El Callao, puesto que el detonante de la situación ha sido precisamente, como se expone luego, una grave situación de inseguridad ciudadana.

Ahora bien, ¿ pueden la violencia y el crimen, aun la criminalidad organizada, con sus nefastas consecuencias sobre la seguridad ciudadana, ser combatidos mediante el recurso al estado de emergencia constitucional? ¿Es ello compatible con el Derecho Constitucional peruano y con el DIDH?

Tales son las interrogantes que el presente artículo se propone dilucidar, en relación con el caso concreto de El Callao, en una breve evaluación preliminar.

\section{Seguridad ciudadana y derechos fundamentales}

La Constitución peruana no reconoce de manera expresa un derecho fundamental a la seguridad ciudadana. Aunque de aquí no se sigue necesariamente que tal derecho no exista o no llegue a existir ${ }^{3}$, lo cierto es que el Tribunal Constitucional, correctamente, ha sostenido de manera reiterada que la seguridad ciudadana "no debe ser observada como un derecho fundamental, sino como un bien jurídico protegido", asociándola a acciones o medidas orientadas a "salvaguardar el desarrollo de la vida comunitaria dentro de un contexto de paz, tranquilidad y orden”, a través del poder de policía, y con vistas a consolidar "una situación de convivencia con 'normalidad"'4

En el mismo sentido se ha pronunciado la Defensoría del Pueblo, institución que asevera lo siguiente:

"La seguridad ciudadana no constituye en si misma un derecho de naturaleza constitucional o legal, pero si un bien juridicamente protegido en tanto conjunto de acciones o medidas destinadas a preservar otros bienes o valores jurídicamente protegidos por nuestro ordenamiento - además de los derechos constitucionales a la vida, integridad, propiedad,

\footnotetext{
Véase la cláusula de derechos fundamentales implícitos, contenida en el artículo 3, Const. Véase STC 2876-2005-HC (caso MALlQui LauRenCE), de 22 de junio de 2005, fundamento 18. Véase también STC 3482-2005-HC (caso Brain Delgado), de 27 de junio de 2005, fundamento 13; STC 05287-2005-HC (caso Rabanal Galdós), de 17 de agosto de 2005, fundamento 14; STC 1889-2005-AA-TC (caso Mata Cuadros), de 9 de diciembre de 2005, fundamento 13 .
} 
etc. - como la tranquilidad pública o paz social, la prevención del delito, uso pacífico de los espacios y vías públicas, erradicación de la violencia, etc."

Pero no solo en el campo del Derecho Constitucional peruano se niega carácter de derecho fundamental a la seguridad ciudadana, ello ocurre también a nivel del DIDH. Así, la Comisión Interamericana de Derechos Humanos (CIDH), tras subrayar la necesidad de contar con "un concepto preciso" de seguridad ciudadana, en tanto ello es condición previa esencial para una adecuada definición de las obligaciones de los Estados conforme a los instrumentos del DIDH aplicables, apunta que, con excepción de la Convención de Belém do Pará, — cuyo artículo 3 recoge el derecho de toda mujer a "una vida libre de violencia, tanto en el ámbito público como privado"-, "en el orden jurídico internacional de los Derechos Humanos no se encuentra consagrado expresamente el derecho a la seguridad frente al delito o a la violencia interpersonal o social"6.

No obstante, estas aproximaciones están lejos de pretender desvincular la seguridad ciudadana de los derechos fundamentales o derechos humanos. Por el contrario, tanto el Tribunal Constitucional y la Defensoría del Pueblo, en el Perú, como la CIDH, en el Sistema Interamericano de Derechos Humanos (SIDH), enfatizan la estrecha relación entre una y otros.

Así, por ejemplo, la Defensoría del Pueblo sostiene que las situaciones que generan inseguridad en la ciudadanía suelen vulnerar o amenazar los derechos a la vida, integridad, libertad y patrimonio de las personas, siendo el resultado de delitos directos, pero también de diversas actividades que llevan a la "degradación social del entorno barrial o vecinal", lo que puede convertir a la inseguridad en "un elemento endémico"7.

Por su parte, la CIDH, con criterio más amplio, considera que, además de los derechos ya mencionados, también están concernidos por la inseguridad ciudadana el derecho a las garantías procesales y el derecho al uso pacífico de los bienes, sin perjuicio de otros derechos ${ }^{8}$.

Como quiera que fuere, lo que resulta importante de tener en cuenta es que, en las últimas décadas, con el fin de las dictaduras y las transiciones democráticas habidas en América Latina, la concepción de seguridad ha cambiado, y ya no más está asociada solo o predominantemente a la seguridad del Estado, sino que, más bien, se conecta decididamente a una concepción de sociedad democrática, para la cual el centro de la preocupación reposa sobre la seguridad de la persona humana y sus derechos fundamentales?.

Como indica el Programa de las Naciones Unidas para el Desarrollo (PNUD), se ha pasado de "la defensa de los intereses neurálgicos de los Estados, como la soberanía y la

\footnotetext{
Véase Defensoría del Pueblo (2008), p. 33; Defensoría del Pueblo (2004), pp. 14 y 41. Véase Comisión Interamericana de Derechos Humanos (CIDH) (2009), párrafo 18.

Véase Defensoría del Pueblo (2008), p. 26. Véase también STC 3482-2005-HC (caso Brain Delgado), de 27 de junio de 2005, fundamento 13; STC 05287-2005-HC (caso Rabanal Galdós), de 17 de agosto de 2005, fundamento 14; STC 1889-2005-AA-TC (caso MATA CuADros), de 9 de diciembre de 2005, fundamento 13. Véase Comisión Interamericana de Derechos Humanos (CIDH) (2009), párrafo 18. Comisión Interamericana de Derechos Humanos (CIDH) (2009), párrafos 5 y 8.
} 
autonomía", a un "enfoque centrado en las personas" y sus derechos, incluido el "derecho a tener una vida digna", de suerte que, para este organismo internacional, la seguridad ciudadana "puede entenderse como una modalidad específica de la seguridad humana", la cual está "relacionada con la seguridad personal y, más específicamente, con amenazas como el delito y la violencia"10.

La CIDH concuerda con esta visión y señala que la seguridad ciudadana "es una de las dimensiones de la seguridad humana y por lo tanto del desarrollo humano", añadiendo que la seguridad ciudadana "se ve amenazada cuando el Estado no cumple con su función de brindar protección ante el crimen y la violencia social, lo cual interrumpe la relación básica entre gobernantes y gobernados"11.

Ahora bien, pese a que no consagra expresamente un derecho fundamental a la seguridad ciudadana, la Constitución peruana sí recoge el concepto de seguridad ciudadana y establece ciertos deberes estatales específicos. En efecto, el artículo 197, modificado por la Ley $N^{\circ} 27680$ (El Peruano, 7 de marzo de 2002), prescribe que las Municipalidades "brindan servicios de seguridad ciudadana, con la cooperación de la Policía Nacional del Perú, conforme a ley"12.

De allí que se haya aprobado la Ley $N^{\circ} 27933$, denominada "Ley del Sistema Nacional de Seguridad Ciudadana” (El Peruano, 12 de febrero de 2003), cuyo artículo 2 establece lo siguiente:

"Se entiende por Seguridad Ciudadana, para efectos de esta Ley, a la acción integrada que desarrolla el Estado, con la colaboración de la ciudadanía, destinada a asegurar su convivencia pacifica, la erradicación de la violencia y la utilización pacifica de las vías y espacios públicos. Del mismo modo, contribuir a la prevención de la comisión de delitos y faltas".

De igual manera, la mencionada Ley crea el Sistema Nacional de Seguridad Ciudadana (SINASEC), definiéndolo como "el sistema funcional encargado de asegurar el cumplimiento de las políticas públicas que orientan la intervención del Estado en materia de seguridad ciudadana, destinado a garantizar la seguridad, la paz, la tranquilidad, el cumplimiento y respeto de las garantías individuales y sociales a nivel nacional para lograr una situación de paz social y la protección del libre ejercicio de los derechos y libertades" (artículo 3).

En definitiva, entonces, aun cuando no se reconozca que existe un derecho fundamental a la seguridad ciudadana, el enfoque adecuado para abordar la problemática actual de la seguridad ciudadana ha de tomar en cuenta la centralidad de la persona humana y de sus derechos fundamentales o derechos humanos, en el marco del Estado de Derecho de una sociedad democrática, para enfrentar los desafíos que el delito y la violencia plantean al orden social y político de los países de América.

\footnotetext{
Programa de las Naciones Unidas para el Desarrollo (PNUD) (2013), p. 5.

Véase Comisión Interamericana de Derechos Humanos (CIDH) (2009), párrafo 2.

Ya el texto original de la Constitución preveía la institución en parecidos términos: "La ley regula la cooperación de la Policía Nacional con las municipalidades en materia de seguridad ciudadana” (artículo 195). Véase ABAD (2015), p. 194 (en especial, nota 26).
} 


\section{El estado de emergencia en la Constitución peruana}

El estado de emergencia es una modalidad del régimen de excepción previsto en el artículo 137.1 de la Constitución peruana. Lo puede declarar el Presidente de la República, con acuerdo del Consejo de Ministros, por plazo determinado, en todo o parte del territorio nacional, "en caso de perturbación de la paz o del orden interno, de catástrofe o de graves circunstancias que afecten la vida de la Nación”. Se diferencia, pues, del estado de sitio, modalidad más grave, que puede ser aplicada ante situaciones de "invasión, guerra exterior, guerra civil, o peligro inminente de que se produzcan” (artículo 137.2, Const.).

Bajo estado de emergencia, puede restringirse o suspenderse el ejercicio de cuatro derechos fundamentales: libertad y seguridad personales, inviolabilidad del domicilio, libertad de reunión y libre tránsito en el territorio nacional. Igualmente, el Presidente de la República puede disponer que las Fuerzas Armadas asuman el control del orden interno, el cual normalmente corresponde a la Policía Nacional del Perú. El plazo máximo es de sesenta días, pero cabe prórroga mediante la expedición de un nuevo decreto presidencial.

Puede decirse, entonces, que el régimen de excepción constitucional, en cualquiera de sus dos modalidades (estado de emergencia o estado de sitio), "supone una disciplina jurídica especial, distinta de la vigente durante la situación de "normalidad constitucional”, la cual apunta a conjurar una grave emergencia que amenaza la propia vida de la nación o la continuidad del Estado"13, lo que se conoce como una "amenaza existencial"14. El resultado de ello es la concesión de poderes excepcionales al Ejecutivo, con la consiguiente modificación de la división de poderes, la habilitación de la suspensión o restricción del ejercicio de determinados derechos y la autorización a ordenar la intervención de las Fuerzas Armadas para enfrentar el peligro que se abate sobre el país ${ }^{15}$.

De allí que el Tribunal Constitucional peruano haya señalado que una de las características del régimen de excepción es la "concentración del poder, con permisión constitucional, en un solo detentador — normalmente el jefe del Ejecutivo-, mediante la concesión de un conjunto de competencias extraordinarias, a efectos de que la acción estatal sea tan rápida y eficaz como lo exijan las graves circunstancias de anormalidad que afronta la comunidad política"16.

\section{El estado de emergencia en El Callao}

El Callao fue declarado bajo estado de emergencia desde el mes de diciembre del año 2015, cuando el Decreto Supremo 083-2015-PCM así lo declaró (El Peruano, 4 de diciembre de 2015). Entre las consideraciones que llevaron a la instauración del régimen excepcio-

\footnotetext{
Véase Siles (2015a), p. 74.

Véase Ackerman (2007), pp. 35-36, 39, 82-83, 87, 95; Pérez (2010), p. 9.

Sobre el estado de excepción en el Perú, puede consultarse, entre otros, EgUiguren (1989), pp. 263-287; Castillo (2005b); Palacios (1988); Power (1990).

16 Véase STC 00002-2008-AI (caso de la Ley 29166, sobre las reglas del empleo de la fuerza por las Fuerzas Armadas en el territorio nacional), de 9 de septiembre de 2009, fundamento jurídico 18 (www.tc.gob.pe, 14 de septiembre de 2009).
} 
nal se mencionó la solicitud del Director de la Policía Nacional de proceder a declarar el estado de emergencia, "a fin de fortalecer la lucha contra la delincuencia y organizada en todas sus modalidades" (sic). También se señaló que en la localidad se había producido un "incremento del índice delictivo" y que en ella "operan organizaciones delictivas dedicadas al tráfico ilícito de drogas, que conlleva la comisión de otros delitos, tales como sicariato, homicidio, lesiones y otros, incluyendo a otras organizaciones delincuenciales dedicadas a la extorsión" (sic).

Para completar la justificación de la medida, el Decreto Supremo 083-2015-PCM, haciendo alusión a una de las causales previstas en el artículo 137.1 de la Constitución, sostuvo que, al haberse producido "actos contrarios al orden interno que afectan el normal desenvolvimiento de las actividades de la población de la Provincia Constitucional del Callao, resulta necesario adoptar las medidas constitucionalmente previstas para restablecer el orden interno".

El estado de emergencia se estableció por el plazo de 45 días y quedaron suspendidos (hay que entender que en su ejercicio) los derechos a la libertad y seguridad personales y a la inviolabilidad del domicilio, en tanto se mantuvo a la Policía a cargo del control del orden interno.

Luego de esta declaración inicial, el estado de emergencia ha sido prorrogado sucesivamente seis veces y se mantenia vigente a la fecha de esta investigación ${ }^{17}$. Los decretos de prórroga han conservado el esquema básico del decreto de instauración, con algunas pocas variaciones. Entre éstas, destaca el haber añadido, como fundamentación, la "obligación del Gobierno Constitucional" de "garantizar el derecho de los ciudadanos al orden, a la tranquilidad pública y a la seguridad"18. También resulta significativo que, desde el primer decreto de prórroga, se indique como finalidad la de "consolidar la lucha contra la inseguridad ciudadana y el crimen organizado en todas sus modalidades". Estas invocaciones específicas al derecho ciudadano al orden, la tranquilidad y la seguridad, así como a la necesidad de combatir la inseguridad ciudadana han aparecido después en todos los decretos supremos de prórroga.

Ninguno de los decretos de prórroga señaló razones específicas para extender el estado de emergencia, ni presentó información y análisis sobre las medidas y acciones adoptadas en el ejercicio de los poderes excepcionales. Tampoco sobre los resultados obtenidos.

En cuanto a la cuestión de los plazos, ha habido algunas oscilaciones, sin justificación aparente. Así, las tres primeras prórrogas repitieron el período de 45 días, mientras que el siguiente decreto (mayo de 2016) amplió el plazo a 60 días (el máximo permitido por

17 Véanse DS 004-2016-PCM (El Peruano, 15 de enero de 2016), DS 013-2016-PCM (El Peruano, 2 de marzo de 2016), DS 024-2016-PCM (El Peruano, 15 de abril de 2016), DS 036-2016-PCM (El Peruano, 31 de mayo de 2016), DS 056-2016-PCM (El Peruano, 30 de julio de 2016), DS 066-2016-PCM (El Peruano, 27 de agosto de 2016).

18 La Constitución peruana consagra el derecho de todas las personas al disfrute de la paz y la tranquilidad (artículo 2.22). 
la Constitución), pero el que siguió a este (julio de 2016) lo redujo a 30 días, habiéndose vuelto al plazo primigenio de 45 días en el último decreto (agosto de 2016).

Es de notar que los dos últimos decretos han sido emitidos por el nuevo Gobierno electo, que al comienzo redujo considerablemente el plazo, pues lo estableció solo por 30 días, frente a los 60 días decretado por el Gobierno anterior la última vez, no obstante lo cual el nuevo Gobierno ha retornado ahora a la prórroga por el plazo de 45 días.

Hay que apuntar también el error, observable en todos los decretos relativos al estado de emergencia en El Callao, consistente en determinar que "quedan suspendidos los derechos constitucionales". Y es que la Constitución peruana de 1993, superando una larga polémica suscitada bajo su predecesora de 1979, estipuló claramente que lo que puede suspenderse o restringirse es "el ejercicio de los derechos constitucionales" (artículo 137.1), esto es, no las garantías ni los derechos mismos ${ }^{19}$.

Resulta sorprendente el error cometido, que se repite decreto a decreto, ya que parece poner de manifiesto no solo el descuido con que se elaboran estos decretos, de modo rutinario y mecánico, sino también resabios de la vieja concepción autoritaria sobre los estados de excepción, en virtud de la cual se entiende que, durante el gobierno de crisis o vigente Constitución de emergencia, desaparecen los derechos y quizá también el Estado de Derecho ${ }^{20}$.

Algunos rasgos que merecen ser destacados del estado de emergencia en El Callao son los siguientes:

A pesar de las extensiones sucesivas del plazo, no se ha hecho uso del máximo permitido por la Constitución (salvo en una ocasión, como ya se advirtió).

Solo se ha decretado la suspensión (hay que entender que del ejercicio) de dos de los derechos previstos en el artículo 137.1 de la Constitución, permaneciendo incólumes los derechos a la libertad de reunión y al libre tránsito en el territorio nacional.

No se ha dispuesto que las Fuerzas Armadas se hagan cargo del orden interno, en reemplazo de la Policía Nacional, con lo que se evita la militarización de las tareas de seguridad ciudadana.

Estas características son relevantes, especialmente si se tiene en cuenta que una investigación anterior, que revisó los decretos sobre estado de emergencia expedidos en el Perú entre los años 1980 y 2011, concluyó que resulta claro que el empleo del "estado de emergencia” por el Presidente de la República, como parte de sus poderes excepcionales, "ha supuesto la aplicación del máximo de severidad que la Constitución habilita: renovación incesante del estado de emergencia, por hechos vinculados a la causal de perturbación de la paz o del orden interno, durante el mayor tiempo permitido, con suspensión de derechos

\footnotetext{
Véase García (1988), pp. 275-288; Palacios (1988), pp. 67-71 y 79-82; Eguiguren (1989), pp. 279-283.

Entre los autores peruanos, MAGDIEL GonZÁLEs ha sostenido, con error, que los estados de excepción acarrean la "negación temporal" o la "suspensión" del Estado de Derecho. Véase GonZales (1991), pp. 19 y 20.
} 
fundamentales, y con intervención de las Fuerzas Armadas, en sustitución de la Policía, para hacerse cargo del control del orden interno"21.

\section{Dos problemas centrales del estado de emergencia en El Callao ${ }^{22}$}

Sin ánimo de exhaustividad, hay que mencionar al menos dos problemas centrales observables en el estado de emergencia en El Callao a la fecha de esta investigación. Estos tienen que ver, en primer lugar, con la causal invocada, relacionada con la problemática de la inseguridad ciudadana; $y$, en segundo término, con la extensión temporal del estado de excepción.

\section{Seguridad ciudadana y mantenimiento del orden interno: ¿afectación de la vida de la Nación?}

El problema central observable en el estado de emergencia en El Callao tiene que ver con la causal invocada, relacionada con la problemática de la inseguridad ciudadana.

Como se ha indicado, el estado de emergencia en El Callao ha sido declarado y prorrogado sucesivamente, invocando la causal de perturbación del orden interno, en relación a una problemática de inseguridad ciudadana que es provocada por la delincuencia común y el crimen organizado. La cuestión que surge, entonces, es si efectivamente se cumplen las exigencias de la Constitución y los tratados internacionales de derechos humanos para la instauración y mantenimiento del estado de excepción.

Es claro que las condiciones de aplicación de las cláusulas de suspensión o derogación, contenidas en la Constitución y en los instrumentos internacionales de protección de los derechos humanos, muestran fuertes rasgos de indeterminación y flexibilidad, como han resaltado diversos autores ${ }^{23}$. Es claro, asimismo, que tales rasgos inclinan a conceder un amplio margen de discrecionalidad a la autoridad encargada de decidir sobre la existencia o no de un estado de emergencia ${ }^{24}$. No obstante, se requiere establecer algunos criterios mínimos que orienten la interpretación adecuada de las exigencias constitucionales e internacionales para la proclamación y renovación de los estados de excepción.

Una cuestión de interpretación de las causales constitucionales del estado de emergencia, de primera importancia, es si es que la mención a "graves circunstancias que afecten la vida de la Nación” es concurrente con las anteriores causales enumeradas en el artículo

\footnotetext{
Véase Siles (2015b), p. 80.

Para el análisis que se propone en esta sección, me valgo de ideas desarrolladas en una investigación anterior. Véase SILES (2016).

23 Véase Bernales (1999), p. 612; Coloma (1985), p.77; Rubio y Bernales (1981), pp. 218 y 219. Véase también Provost (2004), pp. 273-274.

24 Véase Fernández (2014), pp. 614-615; Provost (2004), p. 275.
} 
137.1 de la Constitución. Aunque una desaconsejable lectura literal ${ }^{25}$ puede inclinar a pensar que se trata de una exigencia separada (una nueva causal), en realidad, atendiendo al sentido de la institución del régimen de excepción, hay que recordar que debe haber siempre una "amenaza existencial", de suerte que también en el caso de perturbación de la paz y del orden interno, y en el de catástrofe, deberá verse afectada la vida de la Nación.

El Tribunal Constitucional peruano, sin embargo, no se ha planteado esta cuestión interpretativa y se ha resistido a brindar mayor precisión conceptual sobre las causales del estado de emergencia. En su jurisprudencia ha optado, más bien, por exhortar al legislador democrático a que apruebe un marco normativo sobre los regímenes de excepción previstos en el artículo 137 de la Constitución, en armonía con el DIDH. Tal legislación, en opinión del Tribunal Constitucional peruano, ha de realizar "un desarrollo de los conceptos de perturbación de la paz, del orden interno, de catástrofe o de graves circunstancias que afecten la vida de la Nación para establecer los casos y situaciones que ameritan la declaratoria del estado de emergencia"26.

Ante la ausencia de precisiones de Derecho Constitucional, tanto normativas como jurisprudenciales, es necesario acudir al DIDH, en la medida en que integra el "bloque de constitucionalidad"27. Pues bien, el PIDCP y la CADH exigen que se presente una situación de "amenaza existencial". El artículo 4.1 del PIDCP establece que los supuestos habilitantes han de ser "situaciones excepcionales que pongan en peligro la vida de la nación", mientras el artículo 27.1 de la CADH prevé un "caso de guerra, de peligro público o de otra emergencia que amenace la independencia o seguridad del Estado Parte".

La Corte Interamericana de Derechos Humanos (Corte IDH), siguiendo criterios fijados por su homólogo europeo, ha establecido los requisitos que deben existir para que esté justificado un estado de excepción. Así, afirma que "para que se justifique un estado de excepción es necesario: a) que exista una situación excepcional de crisis o emergencia; b) que esta afecte a toda la población, y c) que constituya una amenaza a la vida organizada de la sociedad"28.

Como señalo en mi estudio antes citado, "la jurisprudencia del Tribunal Europeo de Derechos Humanos (TEDH o ECHR por sus siglas en inglés) sobre el significado de la frase "otro peligro público que amenace la vida de la nación", contenida en el artículo 15.1 de la Convención Europea sobre Derechos Humanos (CEDH), a que se remite la Corte IDH, es aún más explícita y detallada, manteniéndose constante desde el primer

25 Véase Landa (2003), pp. 486, 488 y 495-496; Hesse (2012), pp. 61-63 y 67-69; GUASTini (2001), pp. 263-264. Véase también STC 5854-2005-AA (Caso Lizana Puelles), de 8 de noviembre de 2005, fundamentos jurídicos 12, 17, 32 y 36 (www.tc.gob.pe, 8 de noviembre de 2005).

26 Véase STC 00002-2008-AI (caso de la Ley N²9166, sobre las reglas del empleo de la fuerza por las Fuerzas Armadas en el territorio nacional), de 9 de septiembre de 2009, punto resolutivo 6 y fundamento jurídico 31.a (www.tc.gob. pe, 14 de septiembre de 2009).

27 Véase HaKansson (2009), pp. 180 y 234-238; LANDA (2006), pp. 119-121. Véase también STC 2730-2006-PA/ TC (caso Castillo Chirinos), de 21 de julio de 2006, fundamentos jurídicos 9-15 (www.tc.gob.pe, 27 de julio de 2006).

28 Véase Corte IDH, Sentencia del Caso Zambrano Vélez y otros vs. Ecuador, del 4 de julio de 2007 (fondo, reparaciones y costas), párrafo 46 (disponible en: www.corteidh.or.cr). 
fallo, expedido en el Caso Lawless vs. Ireland, el $1^{\circ}$ de julio de 1961. En efecto, en esta ocasión el TEDH aseveró que "el significado natural y habitual de las palabras 'otro peligro público que amenace la vida de la nación’ es suficientemente claro” y que tales palabras "se refieren a una situación excepcional de crisis o emergencia que afecta a toda la población y constituye una amenaza a la vida organizada de la comunidad que compone el Estado" ${ }^{29}$. Tales criterios han sido reiterados en pronunciamientos posteriores, como por ejemplo el dictado por el TEDH en el Caso A. and Others vs. The United Kingdom $(2009)^{30}$, que es incluso posterior a la decisión adoptada por la Corte IDH en el Caso Zambrano Vélez y otros vs. Ecuador (2007)" ${ }^{31}$.

De otro lado, también ha de tomarse en consideración la Observación General $N^{\circ} 29$ (2001), sobre los “estados de excepción y suspensión de derechos", emitida por el Comité de Derechos Humanos del PIDCP, la cual exige, como "condición fundamental", que la situación excepcional "ponga en peligro la vida de la nación", mencionando expresamente que "no todo disturbio o catástrofe constituye una situación excepcional que ponga en peligro la vida de la nación, como se exige en el párrafo 1 del artículo $4{ }^{32}$.

Estos criterios son confirmados por la doctrina. En el ámbito del DIDH, Amaya Úbeda de Torres se refiere a una situación que "amenaza la existencia organizada de un pueblo, es decir, el sistema político y social del que este dispone como Estado"33. En el terreno del Derecho Constitucional peruano, Enrique Bernales Ballesteros señala que ha de tratarse de "situaciones excepcionales, de extrema gravedad, que amenazan la continuidad del Estado y de la sociedad"34.

Así, pues, a la luz de las consideraciones expuestas, parece claro que el estado de emergencia proclamado y renovado sucesivamente en El Callao no cumple los requisitos para su proclamación y mantenimiento, derivados de la articulación entre el Derecho Constitucional y el DIDH.

No quiere decir que no pueda establecerse válidamente el estado de emergencia en una localidad determinada (como El Callao). Tampoco quiere decir que el desafío existencial no pueda consistir en un problema de inseguridad ciudadana, o en una situación de desborde de la delincuencia común y de la criminalidad organizada. Lo que ocurre es que debe estarse ante una amenaza existencial en los términos expuestos en este acápite. Parece claro que la inseguridad ciudadana en El Callao no afecta a toda la población ni constituye una amenaza a la vida organizada de la sociedad. Ni la nación peruana ni sus instituciones de gobierno están al borde de la disolución a causa de la violencia y el delito.

29 Véase ECHR, Case of Lawless vs. Ireland (judgment), 1 July 1961, paragraph 28 (traducción mía) (disponible en: www.echr.coe.int).

30 Véase ECHR, Case of A. and Others vs. United Kingdom (judgment), 19 February 2009, paragraph 176 (disponible en: www.echr.coe.int).

31 Véase Siles (2016), p. 22 (cita del manuscrito).

32 Véase Comité de Derechos Humanos (2001), párrafos 2 y 3.

Véase Úbeda (2007), p. 581. Véase también, Faúndez (2004), p. 99; O’Donnell (1989), pp. 398-403.

34 Véase Bernales (1999). Véase también Castillo (2005b), p. 5; Espinosa-SaldaÑa (2003), pp. 172-174. 


\section{Estado de emergencia en El Callao y principio de temporalidad}

El principio de transitoriedad o temporalidad es esencial al estado de emergencia, precisamente por su carácter excepcional ${ }^{35}$. No es admisible, en términos constitucionales y del DIDH, que la emergencia devenga en permanente. La "normalización de la emergencia" o la "permanencia de lo temporal" ${ }^{36}$ configuran situaciones anómalas que el ordenamiento jurídico debe recusar.

Las renovaciones sucesivas del estado de emergencia en El Callao, más allá de no haber sido justificadas de manera adecuada, hacen temer justamente que se institucionalice el régimen de excepción también en este ámbito del país, con la consiguiente amenaza de que se extienda a otros lugares y también de que infiltre la vida constitucional toda. Algo que, por cierto, es muy frecuente en la vida constitucional peruana, inclusive en la actualidad ${ }^{37}$.

Desde luego, los controles políticos a cargo del Parlamento debieran ser activados (también, por cierto, para el caso de la determinación de si existe o no una amenaza existencial que justifique la excepción). Con mayor razón, cuando el Tribunal Constitucional, nuevamente, se resiste a brindar precisiones conceptuales, esta vez sobre el principio de temporalidad bajo el régimen de excepción.

En efecto, "en su primera sentencia en la materia (agosto de 2004) el supremo intérprete de la Constitución se refirió a la "transitoriedad" como una característica distintiva del régimen excepcional, mencionando el fenómeno de su "prolongación indebida e inexcusable", pero sin señalar límite alguno a su renovación continua. Cinco años después (septiembre de 2009), en la exhortación que dirige al Congreso de la República al concluir el proceso sobre la constitucionalidad de la Ley $\mathrm{N}^{\circ} 29166$, el Tribunal Constitucional solicita la aprobación de una ley que se ocupe del "plazo de 60 días establecido en el artículo 137 de la Constitución y la naturaleza excepcional de esta medida"” 38 .

En definitiva, atendiendo a la naturaleza excepcional de la institución, el legislador democrático o el propio Tribunal Constitucional mediante su jurisprudencia podrían establecer un tope o un número límite para las prórrogas continuas del estado de emergencia, pues está en su propia naturaleza que la "Constitución de reserva" ${ }^{39}$ no puede volverse permanente.

35 Véase Castillo (2005b), p. 9; Bernales (1999), p. 613; STC 017-2003-AI-TC (caso de la Ley N² 24150, sobre normas a cumplir en los estados de excepción en que las Fuerzas Armadas asumen el control del orden interno), de 16 de marzo de 2004, fundamento jurídico 18.d (www.tc.gob.pe, 23 de agosto de 2004). Véase también Rossiter (2011), pp. 303-304; Provost (2004), p. 271.

36 Sobre el concepto de "normalización de la emergencia", véase ACKerman (2007), p. 70; Gross y Ní Aolárn (2006), p. 228 y ss.; Vergottini (2004), p. 23; Benazzo (2004), p. 4; Dyzenhaus (2002), pp. 28-29.

7 Véase Siles (2015a), pp. 74-84.

38 Véase Siles (2016), pp. 26-27 (cita del manuscrito).

39 Véase Benazzo (2004), p. 32. Pedro Cruz Villalón, por su parte, se refiere a u "ordenamiento de reserva" y a una "Constitución alternativa de emergencia”. Véase CrUZ (1980), p. 12; CRUZ (1984), p. 19. 


\section{A manera de conclusión}

El estado de emergencia proclamado y prorrogado reiteradamente en la Provincia Constitucional de El Callao (Perú), con la finalidad de combatir la inseguridad ciudadana provocada por actividades de delincuencia común y crimen organizado, carece de justificación y de sustento en la Constitución peruana vigente y en los instrumentos del Derecho Internacional de los Derechos Humanos que son vinculantes para el Estado peruano.

El estudio de caso permite una evaluación de la aplicación práctica del instituto de excepción constitucional. Así, se observa, en primer lugar, la aparición de ciertas características que hay que saludar como positivas. Entre ellas están: el que, por lo general, no se haya empleado el plazo máximo permitido por la Constitución, sino plazos menores (salvo en una ocasión); el que no se suspendiera el ejercicio de todos los derechos fundamentales cuya suspensión autoriza la Carta Fundamental peruana; el que no se dispusiera la intervención de las Fuerzas Armadas en el control del orden interno, evitándose de ese modo la militarización de la lucha contra la inseguridad ciudadana.

No obstante, se aprecian también serias deficiencias en el uso del estado de emergencia constitucional en este caso de El Callao. Además de la inadecuación de la fórmula empleada, conforme a la cual se habla de suspensión de los derechos y no de su mero ejercicio - quizá como reflejo de una subyacente concepción autoritaria que considera que el régimen de excepción constitucional suprime los derechos fundamentales y anula el Estado constitucional—, se observan dos problemas de considerable gravedad.

Y es que, por una parte, se incumple la exigencia esencial de que exista afectación de la vida de la nación (lo que la doctrina llama una "amenaza existencial"), exigencia establecida en la Constitución peruana y en los instrumentos del DIDH que son vinculantes para el estado peruano. En particular, se incumplen los estándares fijados jurisprudencialmente por la Corte IDH en el caso Zambrano Vélez y otros vs. Ecuador (2007), caso en el que, siguiendo criterios de tiempo atrás establecidos por su homólogo europeo, el TEDH, la Corte de San José indica que "para que se justifique un estado de excepción es necesario: a) que exista una situación excepcional de crisis o emergencia; b) que esta afecte a toda la población, y c) que constituya una amenaza a la vida organizada de la sociedad”.

Por otra parte, se incumple también el principio de temporalidad o transitoriedad que es consustancial a todo estado de excepción conforme a la Constitución peruana, y que es igualmente reconocido por el DIDH. Las renovaciones sucesivas del estado de emergencia en El Callao conllevan el peligro de retornar a una práctica frecuente en el Perú, a saber, la de la normalización de la emergencia o permanencia de lo temporal. Es necesario, por ello, introducir cambios normativos mediante la actividad del legislador democrático o a través de la propia jurisprudencia del tribunal Constitucional, a fin de limitar las prórrogas continuas del estado de emergencia, fijando un tope o número límite a dicha renovación del régimen excepcional. 


\section{Referencias bibliográficas}

Abad Yupaneui, Samuel (2015): Constitución y procesos constitucionales. Estudio introductorio, legislación, jurisprudencia e índices. Palestra, Lima, 448 pp.

Ackerman, Bruce (2007): Antes de que nos ataquen de nuevo: la defensa de las libertades en tiempos de terrorismo. Península, Barcelona, 320 pp.

Bernales Ballesteros, Enrique (1999). La Constitución de 1993. Análisis comparado. Editora RAo, Lima, 758 pp.

Benazzo, Antonella (2004): L’emergenza nel conflitto fra libertà e sicurezza. G. Giappichelli Editore, Torino, $210 \mathrm{pp}$.

Castillo Córdova, Luis (2005a): Los derechos constitucionales. Elementos para una teoría general. Palestra, Lima, $476 \mathrm{pp}$.

CASTILlo Córdova, Luis (2005b): ¿Se suspenden o restringen realmente los derechos constitucionales? Especial referencia a los procesos constitucionales en los regímenes de excepción. Universidad de Piura, Piura, 35 pp.

Coloma Marquina, José (1985): El régimen de excepción en la Constitución peruana de 1979 y derechos humanos (tesis de bachillerato en Derecho). PUCP, Lima, 131 pp.

Comisión Interamericana De Derechos Humanos (CIDH) (2009): Informe sobre seguridad ciudadana y derechos humanos. Documento OEA (Ser.L/V/II. Doc. 57, de 31 de diciembre de 2009), Washington DC, 116 pp.

Comité De Derechos Humanos (2001): Observación General N² 29. Estado de Emergencia (artículo 4). Documento CCPR/C/21/Rev.1/Add.11, de 31 de agosto de 2001, 8 pp.

Cruz Villalón, Pedro (1980). El estado de sitio y la Constitución: la constitucionalización de la protección extraordinaria del Estado. CEC, Madrid, 476 pp.

Cruz Villalón, Pedro (1984): Estados excepcionales y suspensión de garantías. Tecnos, Madrid, 198 pp.

Defensoría Del Pueblo (2004): Libertad de tránsito y seguridad ciudadana. Los enrejados en las vías públicas de Lima Metropolitana (Informe Defensorial $N^{\circ} 81$ ). Defensoría del Pueblo, Lima, 51 pp.

Defensoría Del Pueblo (2008): ¿Ciudadanos desprotegidos?: Estrategias para fortalecer el Sistema Nacional de Seguridad Ciudadana (Informe Defensorial N ${ }^{\circ}$ 132). Defensoría del Pueblo, Lima, 236 pp.

Dyzenhaus, David (2002): “The Permanence of the Temporary: Can Emergency Powers be normalized?”, en: Daniels, Ronald J., Patrick Macklem y Kent Roach, The Security of Freedom: Essay on Canada's Anti-Terrorism Bill. University of Toronto Press, Toronto, pp. 21-37.

Eguiguren Praeli, Francisco (1989): "El estado de emergencia y su aplicación en la Constitución peruana, 1980-1988”, en: A.A.V.V., La Constitución diez años después. Fundación Friedrich Naumann, Lima, pp. 263-287. 
Espinosa-Saldaña Barrera, Eloy (2003): "Estados de excepción, control jurisdiccional y hábeas corpus. Experiencias y riesgos a la luz del caso peruano", en: Jurisdicción constitucional, impartición de justicia y debido proceso. ARA Editores, Lima, pp. 167-226.

Faúndez Ledesma, Héctor (2004): El Sistema Interamericano de Protección de los Derechos Humanos. Aspectos institucionales y procesales. IIDH, San José, 1054 pp.

García Belaunde, Domingo (1988): “Suspensión de garantías ¿̨o de derechos?”, en Estudios en homenaje al Dr. Héctor Fix Zamudio. AA.VV. México DF, IIJ-UNAM, pp. $275-288$

GonZales Ojeda, Magdiel (1991): La excepcionalidad en la Constitución: los estados de excepción y los derechos humanos en la legislación peruana. L.F. Lann, Lima, 149 pp.

Gross, Oren y Ní Aoláin, Fionnuala (2006): Law in times of crisis: emergency powers in theory and practice. CUP, Nueva York, $516 \mathrm{pp}$.

Guastini, Riccardo (2001): “¿Peculiaridades de la interpretación constitucional?”, en Estudios de Teoria Constitucional, México, D.F., Fontamara, 254-278 pp.

Hakansson Nieto, Carlos (2009): Curso de Derecho Constitucional. Palestra, Lima, $490 \mathrm{pp}$.

Hesse, Konrad (2012): Escritos de Derecho Constitucional. Fundación Coloquio Jurídico Europeo - CEPC, Madrid, 282 pp.

Landa Arroyo, César (2003): Tribunal Constitucional y Estado de Derecho. Palestra Editores, Lima, $1010 \mathrm{pp}$.

Landa Arroyo, César (2006): "Implementación de las decisiones del Sistema Interamericano de Derechos Humanos en el Derecho Constitucional peruano", en: Constitución y fuentes del Derecho. Palestra Editores, Lima, pp. 117-132.

O’Donnell, Daniel (1989): Protección internacional de los derechos humanos. CAJ, Lima, $752 \mathrm{pp}$.

Palacios Mc Bride, Rosa María (1988): La protección jurisdiccional de los derechos humanos durante el régimen de excepción (tesis de bachillerato en Derecho). PUCP, Lima, 176 pp.

PÉREz Royo, Javier (2010): “La democracia frente al terrorismo global”, en: Pérez Royo, Javier (dir.), Terrorismo, democracia y seguridad, en perspectiva constitucional. Marcial Pons, Madrid, pp. 7-12.

Power Manchego-Muñoz, Jorge (1990): Constitución y estados de excepción (la Constitución peruana de 1979). Asociación Acción y Pensamiento Democrático, Lima, 289 pp.

Programa de las Naciones Unidas para el Desarrollo (PNUD) (2013): Informe Regional de Desarrollo Humano 2013-2014. Seguridad ciudadana con rostro humano: diagnóstico y propuestas para América Latina. PNUD, Nueva York, 265 pp.

Provost, René (2004): International Human Rights and Humanitarian Law. CUP, Londres, $464 \mathrm{pp}$. 
Rossiter, Clinton (2011): Constitutional Dictatorship: Crisis Government in the Modern Democracies. Transaction Publishers, Nueva Jersey, 330 pp.

Rubio Correa, Marcial y Bernales Ballesteros, Enrique (1983): Constitución y sociedad política. Mesa Redonda Editores, Lima, 671 pp.

Siles VAllejos, Abraham (2015a): "La emergencia... en el corazón del constitucionalismo peruano: paradojas, aporías y normalización”, en: Themis - Revista de Derecho $N^{\circ} 67$, pp. 74-84.

Siles VAllejos, Abraham (2015b): "La lucha antiterrorista en el Perú: agujeros negros legales, agujeros grises y el arduo camino constitucional. Lecciones peruanas para la guerra contra el terrorismo global”, en: Derecho PUCP $N^{\circ} 75$, pp. 75-94.

Siles Vallejos, Abraham (2016): Problemática constitucional del estado de emergencia en el Perú: algunas cuestiones fundamentales (artículo inédito). Lima, 34 pp.

Úbeda de Torres, Amaya (2007): Democracia y derechos humanos en Europa y en América. Estudio comparado de los sistemas europeo e interamericano de protección de los derechos humanos. Editorial Reus, Madrid, 749 pp.

Vergottini, Giuseppe de (2004): "La difícil convivencia entre libertad y seguridad. Respuesta de las democracias al terrorismo", en: Revista de Derecho Politico $N^{\circ} 61$, pp. 11-36.

\section{Normas citadas}

Constitución Política del Perú (1979).

Constitución Política del Perú (1993).

Convención Americana sobre Derechos Humanos “Pacto de San José, Costa Rica” (1969)

Convención Europea sobre Derechos Humanos (1950)

Decreto Supremo 083-2015-PCM, que declara el Estado de Emergencia en la Provincia Constitucional del Callao (El Peruano, 4 de diciembre de 2015)

Decreto Supremo N ${ }^{\circ}$ 004-2016-PCM, que prórroga de Estado de Emergencia declarado en la Provincia Constitucional del Callao. (El Peruano, 15 de enero de 2016)

Decreto Supremo Nº13-2016-PCM, que prórroga de Estado de Emergencia declarado en la Provincia Constitucional del Callao (El Peruano, 2 de marzo de 2016)

Decreto Supremo N 024-2016-PCM, que prórroga de Estado de Emergencia declarado en la Provincia Constitucional del Callao (El Peruano, 15 de abril de 2016)

Decreto Supremo N 036-2016-PCM, que prórroga de Estado de Emergencia declarado en la Provincia Constitucional del Callao (El Peruano, 31 de mayo de 2016)

Decreto Supremo Nº56-2016-PCM, que prórroga de Estado de Emergencia declarado en la Provincia Constitucional del Callao (El Peruano, 30 de julio de 2016) 
Decreto Supremo Nº66-2016-PCM, que prórroga de Estado de Emergencia declarado en la Provincia Constitucional del Callao (El Peruano, 27 de agosto de 2016)

Ley N ${ }^{\circ} 27680$, Ley de Reforma Constitucional del Capítulo XIV del Título IV, sobre Descentralización (El Peruano, 7 de marzo de 2002)

Ley $N^{\circ}$ 27933, Ley del Sistema Nacional de Seguridad Ciudadana (El Peruano, 12 de febrero de 2003)

Pacto Internacional de Derechos Civiles y políticos (1966)

\section{Jurisprudencia citada}

Corte Interamericana de Derechos Humanos. Caso Zambrano Vélez y otros vs. Ecuador (2007). Fondo, reparaciones y costas. Sentencia de 4 de julio de 2007. Serie C No 166.

Tribunal Constitucional del Perú. Caso de la Ley N²4150, sobre normas a cumplir en los estados de excepción en que las Fuerzas Armadas asumen el control del orden interno (2004). Sentencia de 16 de marzo de 2004. Expediente 017-2003-AI-TC.

Tribunal Constitucional del Perú. Caso Malleui Laurence (2005). Sentencia de 22 de junio de 2005. STC 2876-2005-HC.

Tribunal Constitucional del Perú. Caso Brain Delgado (2005). Sentencia de 27 de junio de 2005. STC 3482-2005-HC

Tribunal Constitucional del Perú. Caso Rabanal Galdós (2005). Sentencia de 17 de agosto de 2005. STC 05287-2005-HC.

Tribunal Constitucional del Perú. Caso Lizana Puelles (2005). Sentencia de 8 de noviembre de 2005. Expediente 017-2003-AI-TC.

Tribunal Constitucional del Perú. Caso Mata Cuadros (2005). Sentencia de 9 de diciembre de 2005. STC 1889-2005-AA-TC.

Tribunal Constitucional del Perú. Caso de la Ley N²9166, sobre las reglas del empleo de la fuerza por las Fuerzas Armadas en el territorio nacional (2009). Sentencia de 9 de septiembre de 2009. Expediente 00002-2008-AI.

Tribunal Europeo de Derechos Humanos. Case of Lawless vs. Ireland (1961). Sentencia de 1 de julio de 1961.

Tribunal Europeo de Derechos Humanos. Case of A. and Others vs. United Kingdom (2009). Sentencia de 19 de febrero de 2009. 
